\title{
IMPROVING \\ THE U.S. \\ IMMIGRATION \\ SYSTEM IN THE \\ FIRST YEAR \\ OF THE BIDEN \\ ADMINISTRATION
}

T. Alexander Aleinikoff

University Professor

Director, Zolberg Institute on

Migration and Mobility

The New School

Donald Kerwin

Executive Director,

Center for Migration Studies

of New York

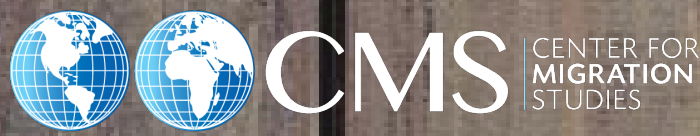

THE

NEW SCHOOL

NOVEMBER 2020
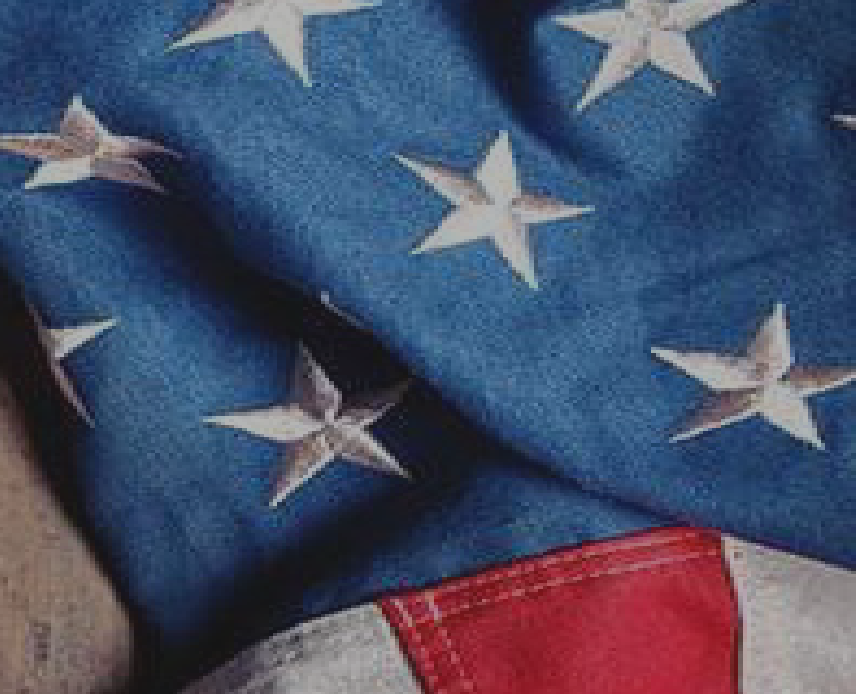
This paper was prepared in consultation with an experts group that included the following members: DanielaAlulema, Muzaffar Chishti, Mark Greenberg, Lucas Guttentag, Josiah Heyman, Susan Martin, Daniel Martinez, Doris Meissner, Michelle Mendez, Charles Wheeler, Stephen Yale-Loehr and Wendy Young.

While the analysis and recommendations of the paper draw from the work and advice of the experts group, the paper does not necessarily represent the views of individual members of the group.

Several experts drafted papers, including subsequently published papers on the U.S. resettlement program and border enforcement, whose analyses and recommendations informed this paper.

\section{PROPOSALS}

1. REFUGEE POLICY.

- Immediately initiate consultations with Congress to increase refugee admissions in Fiscal Year 2021 and to appropriate funding toward this goal

- Meet with U.S. stakeholders to restore credibility and support for refugee resettlement; revoke Executive Order permitting states and localities to prevent refugee resettlement

- Endorse the Global Compact on Refugees

- Review and adjust, as needed, screening measures and COVID-19 restrictions

2.ASYLUM

- Terminate the Migrant Protection Protocols

- Withdraw the Centers for Disease Control and Prevention order closing the border and permitting "expulsions"

- Withdraw from the Asylum Cooperative Agreement with Northern Triangle countries

- Withdraw regulations denying asylum to persons who transit through a third country before arriving in the U.S. or who apply for asylum at the border between ports of entry

- Withdraw Attorney General opinions in Matter of A-B- and Matter of L-E-A-, concerning the definition of "particular social group" under U.S. asylum law

- Withdraw the proposed rule on asylum procedures and standards and the final rule on employment authorization

3. TRAVEL BANS.

- Revoke the bans

4. LEGAL IMMIGRATION REFORMS.

- Return to the status quo ante definition of "public charge"

- Interpret the INA to allow TPS recipients who are immediate relatives of U.S. citizens to be eligible to apply for adjustment of status

- End unnecessary USCIS investigations, vetting and other requirements that have led to lengthy processing delays

- Issue a proposed regulation that decreases fees to a level commensurate with the time and cost to process applications, after scaling back excessive vetting and other extraneous practices and that permits fee waivers based on public benefit receipt 
- Permit new registrations and consider updating the class of DACA-eligible persons

- Reject requirement of "exceptional circumstances" for the granting of advance parole for DACA recipients

- Authorize "parole-in-place" permitting eligibility for adjustment of status

6. IMMIGRATION DETENTION.

- Affirm that detention should be the exception and used only when strictly necessary to ensure appearance in proceedings or to protect public safety

- Expand and improve Alternative-to-Detention programs

- End the use of private corporations to administer immigration detention centers

- Strengthen mechanisms for detention oversight

7. BORDER ENFORCEMENT AND ACCOUNTABILITY

- Defund construction of the border wall

- Review CBP stop, search and seizure policies and programs

- Change CBP's culture

- Strengthen systems to handle and investigate complaints and apply disciplinary processes

- Limit the reach of expedited removal

- Ensure appropriate reception, care and treatment of unaccompanied children at the border and throughout the U.S. immigration system

8. INTERIOR ENFORCEMENT

- Restore meaningful enforcement priorities and prosecutorial discretion to the U.S. immigration system

- Limit the role of local and state authorities in immigration enforcement; restore PEP and end section $287(\mathrm{~g})$ MOAs

9. IMMIGRATION-RELATED CRIMINAL PROSECUTIONS.

- Deprioritize prosecutions for improper entry and re-entry, and forego prosecutions of asylum-seekers

10. LEGAL ACCESS AND REPRESENTATION; ADJUDICATION BACKLOGS.

- Strengthen and expand the LOP, NQRP and BIA Pro Bono programs

- Promote and expand the universal representation model

- Ensure that all unaccompanied children have legal counsel

- Establish an inter-agency working group to develop actionable proposals to reduce immigration court and affirmative asylum backlogs

11. COVID-RELATED POLICES

- Undertake immediate review of the bans

- Release at-risk detainees

12. SEGREGATION OF RESPONSIBILITIES WITHIN DHS.

- End the practice of Border Patrol agents serving as Asylum Officers; require CBP officers to abide by their legal responsibility to refer migrants subject to expedited removal and who communicate fear of return to "credible" or "reasonable" fear interviews

- Limit referrals to removal proceedings to cases involving fraud or when USCIS is statutorily required to refer 


\section{INTRODUCTION}

The last four years have brought significant changes in federal policies-and the national discourseon immigration. Presidential proclamations have denied entry to millions of non-citizens. Regulations and administrative practices have blocked and slowed the admission of legal immigrants. Processing delays, case backlogs and fee increases have made access to visas and immigration relief unattainable for countless immigrants and their families. U.S. businesses have been saddled with new bureaucratic requirements that diminish their productivity, competitiveness and ability to create jobs. The administration has attempted to end the Deferred Action for Childhood Arrivals (DACA) program and to eviscerate the Temporary Protected Status (TPS) program.

Refugee admissions have been dramatically reduced, and community-based infrastructures that sustain refugee resettlement have been decimated. The ability to seek asylum at the southwest border has all but ended, and legitimate asylum claims have been foreclosed by executive fiat. The COVID-19 pandemic has occasioned additional restrictions on refugee admissions and asylum. Legal access and due process have been curtailed.

The immigrant detention system has been expanded, used as a deterrent, and further privatized. It has also served as a vector for the spread of COVID-19. Billions of dollars have been spent on new barriers at the border. Border officials have cruelly separated thousands of children from their parents and consigned others to indefinite detention with their parents. Meaningful immigration enforcement priorities have been abandoned, and enforcement resources have been diverted to undocumented residents with families and strong community ties in the United States. The Department of Homeland Security (DHS) has been consistently misused as a political tool and has been badly mismanaged. The mission statement of U.S. Citizenship and Immigration Services (USCIS) has been re-written, deleting the description of the United States as a "nation of immigrants."

The new administration will face substantial challenges in putting immigration and refugee policy back on track-not just reversing ill-advised policies of the past four years but also improving a system that was in need of reform well before the current administration took office. In this paper, we highlight a number of reforms that we believe should be prioritized by the Biden administration. We have not attempted to offer a comprehensive list of reforms. We have focused on changes in policies and practices that will have significant impact and that can be adopted through executive action, such as new regulations, the withdrawal of prior executive branch declarations and decisions and the settlement of lawsuits. In doing so, we acknowledge that, on many issues, broader reform will be necessary and will require legislation. ${ }^{[1]}$

We believe that the foundation for these reforms can and should be established by a presidential address (or addresses) early in the new president's term. President Biden would affirm the fundamental values and principles that animate the U.S. immigration system, including description of the United States as a country of welcome, a firm commitment to refugee protection and assistance, respect for due process and non-discrimination in enforcement, the importance of protecting and supporting immigrant communities and promotion of a legalization program for long-staying undocumented migrants, those who entered the country as children and other deserving groups.

[1] Legislative reforms could include: comprehensive immigration reform, the establishment of an Article I immigration court and measures to eliminate a large backlog of cases, DREAM Act-like legislation and the NO BAN Act, as well as additional statutes that would ratify the administrative actions proposed here (such as repealing section $287(\mathrm{~g})$, establishing legal representation programs and imposing restrictions on detention). 
The last four years' promotion of fear and prejudice must be replaced with an affirmation of the importance of immigration to U.S. families, U.S. businesses and the future well-being of the nation.

Successful immigration policy reform will depend upon the quality and coordination of the top personnel in a number of federal agencies as well as effective leadership by the White House. The new administration will need to pay particular attention to the knowledge, qualifications and character of those selected to fill these positions.

Our recommendations fall into the following categories:

- Refugee policy

- Asylum

- Travel bans

- Legal immigration

- DACA

- Detention

- Border enforcement and accountability

- Interior enforcement

- Criminal prosecutions

- Legal access and representation; adjudication backlogs

- COVID-19-related policies

- Segregation of responsibilities within DHS 


\section{REFUGEE POLICY}

In one of its earliest actions, the Trump administration suspended the admission of refugees and barred Syrian refugees from entering the U.S. The refugee resettlement program was restarted at a lower admissions ceiling, and each year of the Trump administration the number of authorized admissions declined to new historically low levels. Authorized admissions are now more than 80 percent lower than the final year of the Obama administration, and actual admissions are even lower. The decrease in refugee admissions has kept families separated and has depleted the network of voluntary agencies and their community-based partners that have built and sustained the resettlement program for decades. The United States has lost its global role and reputation as a leader in refugee protection at a time when the number of displaced persons around the world is at its highest level since World War II. The Trump administration's actions and rhetoric have undermined a long-standing bipartisan commitment to refugee resettlement and protection.

\section{PROPOSALS FOR ACTION}

\subsection{Immediately initiate consultations with Congress to increase refugee admissions in Fiscal Year 2021 and to appropriate funding toward this goal}

The Trump administration set a goal of 18,000 admissions for FY2020. Because of delays in processing and the suspension of the program due to the COVID-19 crisis, admissions fell below 12,000 for the year. Historically, authorization for refugee admissions has averaged 98,000 per year. The Biden administration should commit to fully rebuilding and strengthening the community-based resettlement infrastructure and should seek to steadily expand admission levels accordingly. To that end, it should seek funding from Congress to significantly raise the FY2021 admission ceiling of 15,000, a record low, which President Trump set without consulting with Congress as required by statute.

\subsection{Meet with U.S. stakeholders to restore credibility and support for refugee resettlement; revoke Executive Order permitting states and localities to prevent refugee resettlement}

The Trump administration's cut in refugee admissions has devastated the network of voluntary agencies, their community-based partners and state and local offices that support resettlement. Furthermore, President Trump issued an Executive Order (EO) permitting states and localities to prevent the resettlement of refugees in their communities. ${ }^{[2]}$ A strengthened consultation process should be designed to increase transparency and support for the program by localities, states and Congress.

\subsection{Endorse the Global Compact on Refugees}

The United States was one of two countries (the other was Hungary) that refused to endorse the 2018 Global Compact on Refugees (GCR). The GCR establishes goals of increased international responsibility sharing, state coordination, aid to hosting states, refugee self-reliance and progress on solutions to refugee situations. These goals are fully consistent with the traditional aims of U.S.

[2] Forty-three states and nearly 100 localities had consented to the resettlement of refugees in their jurisdictions before the EO was enjoined by a federal court in January 2020. 
refugee policy. The GCR is non-binding; joining the Compact would impose no legal obligations on the United States. Endorsing the Compact would demonstrate U.S. recommitment to global cooperation on refugees.

\section{The Biden administration should commit to fully rebuilding and strengthening the community-based resettlement infrastructure and should seek to steadily expand admission levels accordingly.}

\subsection{Review and adjust, as needed, screening measures and COVID-19 restrictions}

Enhanced screening measures put in place before and during the Trump administration, as well as the COVID-19 restrictions on admissions, jeopardize timely resettlement of refugees. Robust screening is necessary to ensure the program's security and public support for it. However, screening must be completed in a timely manner to ensure that applicants are not required to repeat vetting processes. In addition, screening should be based on the best and most current intelligence and on conditions in refugee-producing countries.

\section{ASYLUM}

The Trump administration has decimated the U.S. asylum system. It has sought to deter asylumseekers from arriving at the southern border by adopting a plethora of new regulations, putting pressure on Mexico and Central American states to aid in enforcement and stationing the military at the border. It has used the COVID-19 crisis to authorize the expulsion of asylum-seekers without affording them guarantees provided by U.S. immigration law and international law. The Attorney General has issued decisions that make it extremely difficult for persons fleeing gender-based or gang violence to be granted asylum in the United States. The administration has stiffened rules for granting work authorization. In June 2020 , proposed regulations were issued that would dramatically alter legal standards for asylum cases.

\section{PROPOSALS FOR ACTION}

\subsection{Terminate the Migrant Protection Protocols}

Under the supremely misnamed Migrant Protection Protocols (MPP), tens of thousands of asylum-seekers have been returned to Mexico, where they await U.S. asylum hearings, or have been returned to their home states. Returned asylum-seekers in Mexico (including many children) are living in desperate circumstances, without adequate shelter, sanitation or protection from kidnapping and sexual assault. Because of the COVID-19 crisis, adjudication of their cases has been postponed indefinitely. The goal of these policies is to deter the arrival of asylum-seekers and to compel those already at the border to give up their claims and return home.

DHS should terminate MPP and establish an orderly process permitting asylum-seekers processed under MPP to enter the United States in an orderly and humane fashion to pursue their claims. As an administrative policy that has not been codified by regulation, MPP can be terminated by rescinding the related policy guidance. 


\subsection{Withdraw the Centers for Disease Control and Prevention (CDC) order closing the border and permitting "expulsions"}

Invoking a provision of the Public Health Service Act over the objections of career CDC officials, the CDC issued an order authorizing immigration authorities to expel persons at the border without a formal removal proceeding or adjudication of claims for asylum. These measures, which have been extended indefinitely, have all but ended processing of asylum-seekers at the U.S. southern border.

The CDC order should be withdrawn, and the interim final rule should be modified to expressly require the government to comply with U.S. and international law related to the treatment of asylum-seekers, refugees and unaccompanied children whenever it undertakes emergency measures to respond to public health crises.

Persons who meet the credible fear standard should be permitted to remain in the United States during the adjudication of their asylum claims. The return of unaccompanied children should be prohibited; children should be afforded the protection of processes provided by the Trafficking Victims Protection Reauthorization Act (TVPRA) of 2008 and expeditiously transferred to the Office of Refugee Resettlement (ORR).[3]

\subsection{Withdraw from the Asylum Cooperative Agreements with Northern Triangle countries}

The United States has entered into agreements with the Northern Triangle countries-Guatemala, El Salvador and Honduras-that permit the U.S. government to send asylum-seekers to those states for the processing of their asylum claims. Several hundred asylum-seekers in the United States have already been transferred to Guatemala. The asylum systems of Guatemala, El Salvador and Honduras are not able to fairly and efficiently process a large number of cases. There is a significant risk that sending asylum-seekers to Central America violates U.S. commitments to the binding international principle of non-refoulement.

The U.S. asylum system has the capacity to process the number of cases being transferred to Central American states. The agreements should be terminated, which can be accomplished by presidential order, and the DHS interim final rule that implements the Agreements should be withdrawn.

\subsection{Withdraw regulations denying asylum to persons who transit through a third country before arriving in the United States or who apply for asylum at the border between ports of entry}

In an attempt to prevent persons arriving at the Southwest Border from being granted asylum, the Trump administration adopted regulations that deny asylum to persons who did not apply for asylum in a third country during their travel to the United States and to persons arriving in the United States who applied for asylum other than at a port of entry.

[3] USCIS should also create a process to identify stateless persons, provide them with appropriate documentation and information to seek any immigration benefits for which they might be eligible, and make them eligible for deferred action and work authorization. Ultimately, Congress should create a path to permanent residence for this population. 
The Biden administration should rescind these rules or halt their implementation. There is overwhelming evidence that common transit countries have inadequate and poorly resourced asylum systems that cannot provide meaningful protection to asylum-seekers. The appropriate standard for persons who have travelled through a third country is whether they have been offered legal residence in another country. Mere travel through a country where a person could have applied for asylum does not meet that standard. Further, federal immigration law permits persons to file for asylum wherever they are located in the United States.

\section{There is a significant risk that sending asylum-seekers to Central America violates U.S. commitments to the binding international principle of non-refoulement.}

\subsection{Withdraw Attorney General opinions in Matter of A-B- and Matter of L-E-A-, concerning the definition of "particular social group" under U.S. asylum law}

In Matter of A-B-, Attorney General Sessions adopted a narrow interpretation of the term "membership in a particular social group," which is one basis for qualifying for asylum under international law and U.S. law. The result is to severely constrict asylum eligibility for victims of gender-based and gang violence. In Matter of L-E-A-, Attorney General Barr expressed skepticism that members of a family could constitute a "particular social group." These decisions are inconsistent with well-developed standards for asylum.

Using the certification authority, the new Attorney General should withdraw the decisions in Matter of A-B- and Matter of L-E-A-, and issue new decisions (and related USCIS and Executive Office for Immigration Review (EOIR) guidance) reaffirming prior law and the availability of asylum for victims of persecution by non-state actors.

\subsection{Withdraw the proposed rule on asylum procedures and standards and the final rule on employment authorization}

In June 2020, the administration published a proposed rule that would provide new interpretations of standards in asylum proceedings and impose significant procedural barriers in asylum cases. Among many other changes, the rule would deny gender as a basis for persecution; thus, most women whose home states will not protect them against domestic violence would now be ineligible for asylum.

The administration also issued a final rule that established new rules on eligibility for work authorization. Previously, applicants could receive work authorization six months after filing their claim. Under the new rule, applicants are not eligible for one year after filing or if they entered the United States other than at a port of entry.

These rules make radical changes in well-established legal norms of refugee protection, which are recognized around the world and were adhered to by the United States. Punitive in nature, these rules do not advance any legitimate goal in protecting persons fleeing serious harm in their home countries. The proposed rule and the final rule should be withdrawn. 


\section{TRAVEL BANS}

One of the first actions of the Trump administration was to ban immigration from seven predominantly Muslim countries. The ban was rewritten twice in response to lower court decisions and eventually upheld by the Supreme court. Subsequently, the President has imposed bans on persons from six additional countries (among them four African countries, including Nigeria, Africa's most populous country), asylum-seekers arriving in the United States between ports of entry and Chinese students and researchers seeking to enter as non-immigrants.

In issuing these sweeping and unprecedented bans on legal admission, the administration has relied upon section 212(f) of the Immigration and Nationality Act (INA), which authorizes the President to suspend entry of classes of foreign nationals whose entry he determines "would be detrimental to the interests of the United States." While the administration has purported to justify these bans on security grounds, no persuasive evidence has been offered in their support; it is plain that particular countries and groups have been targeted based on discriminatory grounds of religion and possibly race as well. Congress has not adopted legislation approving these extraordinary exercises of presidential power.

\section{PROPOSAL FOR ACTION}

\subsection{Revoke the bans}

An incoming administration should immediately revoke the section 212(f) proclamations issued by President Trump, except those that sanction only specified officials or individuals because of particular activity that injures the United States and undermines its interests (e.g., Venezuela sanctions in $\mathrm{EO} 13850$ ). Any new bans should meet the standards and rules provided for in the NO BAN legislation (HR 2214).

\section{LEGAL IMMIGRATION REFORM}

Over many administrations and Congresses, there has been a strong, bipartisan consensus in support of legal immigration and of qualified immigrants advancing to more permanent and secure statuses leading to naturalization. As a recent study shows, this process benefits immigrants, their families and the nation. Legal status also reduces the undocumented population, a bipartisan goal.

The Trump administration has taken a different tack. It has pursued an array of strategies to impede and block the path to permanent residence and citizenship for disfavored populations, including family members of U.S. citizens and lawful permanent residents (LPRs), lower-income working class persons and persons from Muslim-majority countries. ${ }^{[4]}$

[4] Actions relating to refugees and DACA and TPS recipients are discussed later in this report. 


\section{PROPOSALS FOR ACTION}

\subsection{Return to the status quo ante definition of "public charge"}

On February 24, 2020, USCIS put into effect its final rule on the "public charge" grounds of inadmissibility. A decision by a federal appeals court in November 2020 has permitted the government to begin enforcing the rule. ${ }^{[5]}$

Guidelines issued by the U.S. Immigration and Naturalization Service (INS) in 1999 had defined a "public charge" as an immigrant who was primarily dependent on the government for cash assistance for income maintenance or long-term institutionalization. The INS guidelines directed immigration officers to consider the "totality of circumstances"-i.e., the applicant's age, education and other characteristics-in assessing whether he or she was likely to become primarily dependent on public support. The new rule defines a public charge as a person who is likely to receive any of a specified list of public benefits for more than 12 months in a 36-month period; i.e., cash benefits and, in an expansion, Supplemental Nutrition Assistance Programs (SNAP), Medicaid (with exceptions), Section 8 Housing Assistance and public housing.

The new rule assigns weight to various factors to be considered in the totality of the circumstances test that will likely prevent large numbers of intending immigrants from securing permanent status, particularly persons otherwise eligible for family-based visas. An analysis of the rule's potential effect shows that it would deny admission and adjustment to large numbers of working class persons who contribute substantially to the U.S. economy and have U.S. citizen and LPR family members. The rule would also indirectly hurt the family members of persons subject to it. Of further significance is the public charge rule's chilling effect: immigrants and members of their households, including U.S. citizen children, will fail to apply for benefits to which they are entitled. According to one study, this occurred even in anticipation of the rule.

The new public charge rule is also redundant. Since implementation of the Illegal Immigration Reform and Immigrant Responsibility Act of 1996 (IIRIRA), U.S. citizens and LPRs who petition for family members have been required to demonstrate that they can support them at an income of at least 125 percent of the federal poverty guidelines until they become naturalized citizens or earn 40 qualifying quarters of work. On October 2, 2020, USCIS issued a proposed rule to tighten sponsorship requirements.

USCIS should use the appropriate rule-making process to return to the status quo ante, which defined a public charge as a person who is primarily dependent on the government for cash assistance for income maintenance or long-term institutionalization.

\subsection{Interpret the INA to allow TPS recipients who are immediate relatives of U.S. citizens to be eligible to apply for adjustment of status}

The INA requires an applicant for adjustment to lawful permanent residence to have been "inspected and admitted or paroled." The Trump administration interprets this requirement, as did the Obama administration, to bar the adjustment of Temporary Protected Status (TPS) recipients who entered without inspection.

[5] Cook County v. Wolf, 7th Cir., Nov. 4, 2020. 
An analysis of the rule's potential effect shows that it would deny admission and adjustment to large numbers of working class persons who contribute substantially to the U.S. economy and have U.S. citizen and LPR family members.

Applicants who have been "inspected and admitted or paroled" and are the spouses, parents or children of U.S. citizens are eligible to file for adjustment of status. A growing number of courts have rejected the Trump administration's interpretation of the INA, concluding that a grant of TPS constitutes a "lawful admission" for purposes of eligibility for adjustment of status. ${ }^{[6]} \mathrm{A}$ typical fact pattern involves a person who entered the United States without inspection, applied for and was granted TPS, and then becomes the beneficiary of an approved I-130 petition filed by a U.S. citizen spouse or child over 21 years of age.

Thousands of TPS recipients from El Salvador, Honduras, Nicaragua, Nepal and other countries would benefit if a grant of TPS is considered an admission. DHS should issue guidance adopting an interpretation of the INA allowing TPS recipients who are the spouses, parents or children of U.S. citizens to adjust status in the United States.

\subsection{End unnecessary USCIS investigations, vetting and other requirements that have led to lengthy processing delays}

Delays in USCIS processing of family-based applications and petitions are at unacceptable levels. The processing time at the Potomac Service Center for an LPR filing to sponsor a spouse or child is between two to three years. For a U.S. citizen filing to sponsor a sibling, the processing time at the California Service Center is eleven years. For a survivor of domestic violence seeking relief under the Violence Against Women Act, the processing time for an I-360 petition at the Vermont Service Center is two years. USCIS has also eliminated the requirement that requests for Employment Authorization Documents (EADs) be processed in 90 days, resulting in monthslong delays in receiving work authorization. These backlogs will spike further if USCIS furloughs staff in response to revenue shortfalls.

The Trump administration's unnecessary expansion of in-person interviews and related "extreme vetting" adds time and burdens to this already unduly long process. Cases with small errors or issues that were previously resolved through customer service and "InfoPass" appointments are being denied, forcing applicants to restart the process, resulting in USCIS repeating adjudicatory steps. Recent changes in the USCIS's policy allow the agency to deny applications and petitions outright rather than issue a Request for Evidence (RFE) or a Notice of Intent to Deny (NOID) to obtain additional information or documentary proof. Denials also place an unfair financial burden on applicants, forcing them to again pay filing fees to refile a case. ${ }^{[7]}$

When cases languish in review, permanent status becomes illusory for large numbers of qualified immigrants. Applicants cannot make long-term plans for their future. Travel within the United States and abroad becomes more complicated or impossible, and work authorization may lapse,

[6] E.g., Velazquez v. Barr, 8th Cir., Oct. 27, 2020.

[7] Exacerbating matters, USCIS has also funneled USCIS application funding to ICE in recent years. 
leading to loss of jobs, driver's licenses and other hardships. These delays also work immense hardship on the U.S. citizen, LPR and corporate sponsors of would-be immigrants.

USCIS should end unnecessary investigations and excessive vetting, resolve (without denying) cases with inconsequential errors and reinstate the policy requiring adjudicators to issue an RFE or NOID before issuing a denial.

\subsection{Issue a proposed regulation that decreases fees to a level commensurate with the time and cost to process applications, after scaling back excessive vetting and other extraneous practices, and that permits fee waivers based on public benefit receipt}

Congress requires immigration application processing expenses - the bulk of USCIS' budgetto be funded by application fees. Under the Trump administration, USCIS has also introduced a number of extraneous requirements to immigration applications and petitions that are resource-intensive and do not go to the merits of the adjudication process. While fees have steadily increased over the years, the increases have not produced improvements in management and efficiency. High fees operate as a disincentive and barrier for many immigrants seeking permanent residence or naturalization.

On August 3, 2020, USCIS issued a final rule that would increase fees for a variety of applications and petitions, including employment authorization, a petition for a relative, adjustment to permanent resident status (taking into account the cost of other concurrently filed applications) and naturalization (from $\$ 649$ to $\$ 1,170$ ). For the first time, the rule would also assess a fee for affirmative asylum applications $(\$ 50)$. It would restrict fee waivers by, in part, eliminating the ability of applicants to file for a waiver based on receipt of a means-tested public benefit. Yet, fee waivers are crucial in providing individuals and families with access to immigration benefits and (ultimately) naturalization. On September 29, 2020, a federal judge enjoined implementation of the rule.

\section{PRESERVE DACA}

In DHS v. Regents of the University of California (2020), the Supreme Court invalidated President Trump's termination of the DACA program. At the same time, there remains a direct challenge to DACA's validity pending before the same court that invalidated the Deferred Action for Parents of Americans and Lawful Permanent Residents (DAPA) program. A legislative solution is needed for undocumented persons who arrived in the United States as children. However, there are several steps the Biden administration should take immediately to preserve and enhance the DACA program pending a legislative solution.

\section{PROPOSALS FOR ACTION}

\subsection{Permit new registrations and consider updating the class of DACA-eligible persons}

The original DACA program, established by President Obama, excluded many potential 
applicants due to age limits ${ }^{[8]}$ and the requirement of five years of continuous residence prior to June 15, 2012 (when DACA was announced). In addition, President Trump's cancellation of the program in September 2017 prevented thousands of eligible immigrants to apply for DACA. If the application period is reopened and DACA reinstated, those who did not previously applydue to financial barriers, the educational requirement, age, or other reasons-might now apply.

The new administration should:

- Aggressively defend the DACA program in the pending legal challenge to its validity and take steps to preserve the program;

- Permit the filing of new DACA applications;

- Affirm that persons who turned 15 years old or have met the educational requirement after September 2017 are eligible;

- Consider removing the upper bound age limit of less than age 31; raising the age limit (at entry) from age 16 to age 18 to qualify; and updating the continuous residence requirement to require five years of continuous residence prior to the date of the restarting of the program;

- Restore granting DACA for two-year terms;

- Provide for advance parole for humanitarian, educational, family- and work-related reasons; and

- Work with Congress to pass legislation that provides a path to citizenship for DACA recipients and other undocumented residents who arrived in the United States as children.

\subsection{Reject requirement of "exceptional circumstances" for the granting of advance parole for DACA recipients}

While the Supreme Court's 2020 decision invalidated President Trump's termination of the DACA program, it did not rule directly on other actions that cut back the program. During the Obama era, DACA beneficiaries were eligible for advance parole, permitting them to leave the United States (e.g., for family emergencies or educational purposes) and return. In response to the Supreme Court opinion, DHS announced that it would reject applications for advance parole "absent exceptional circumstances." The new administration should rescind the "exceptional circumstances" requirement, and allow for advance parole for humanitarian, educational, family- and work-related reasons.

\subsection{Authorize "parole-in-place" permitting eligibility for adjustment of status}

To be eligible for adjustment of status, a non-citizen must be "inspected and admitted or paroled." DACA beneficiaries who entered without inspection are not able to meet this requirement unless they have received advance parole. ${ }^{[9]}$ Under INA section $212(\mathrm{~d})(5)(\mathrm{A})$, the DHS Secretary can exercise discretion to grant parole for "urgent humanitarian reasons or significant public benefit."

The new Secretary should create a "parole-in-place" program for DACA recipients unable to meet the "inspected and admitted or paroled" requirement. Such a program, already established for family members of select military personnel and veterans, would obviate the need for DACA recipients to leave the country-becoming subject to bars on re-entry-in order to adjust status.

[8] Upon arrival, DACA applicants were required to be under 16 years of age; upon application, applicants must be older than 15 years of age, but under 31 years of age.

[9] Those who overstayed visas after a lawful entry are not barred from adjustment. 


\section{IMMIGRATION DETENTION}

Immigration detention has increased dramatically over the years, from an average of 8,500 persons detained daily in 1996 to roughly 34,000 in the Obama era and 56,000 in the Trump era (before falling in response to migration-related pandemic developments). Congress increased ICE's detention operations budget in both FY2O18 and FY2019. For FY2O21, the Trump administration requested funding for ICE detention at \$3.1 billion in order to bring daily detention capacity to 60,000 people. It also committed to the further privatization of the detention system.

\section{PROPOSALS FOR ACTION}

\subsection{Affirm that detention should be the exception and used only when strictly necessary to ensure appearance in proceedings or to protect public safety}

As a general rule, persons in immigration proceedings should not be detained. Immigration detention should be rare and used only when strictly necessary to either ensure that non-citizens appear for their removal proceedings or to protect the public. In the overwhelming majority of cases, DHS can achieve these goals through means less restrictive than confinement in prisonlike facilities. Restrictions or conditions placed on non-citizens to ensure their appearance in immigration court or their actual removal should be the least restrictive, and non-punitive, means necessary to further these goals. Moreover, as discussed below, even when detention is statutorily mandated, it should not preclude the use of alternative forms of detention.

DHS should issue policy guidance providing that "detention" will be used only when its underlying purposes - to ensure appearances in deportation processes or protect public safetycannot be achieved through other, less intrusive means. The number of detained people should also be limited by establishing prosecutorial discretion guidelines (discussed below) that apply to all U.S. immigration enforcement programs. These guidelines should presumptively provide for the parole of members of vulnerable populations, such as pregnant women, persons with disabilities or medical problems, the elderly, parents and caregivers, LGBTQ individuals and detainees between age 18 and 21 who (if released) may be able to secure Special Immigrant Juvenile visas in their states of residence. ICE should also review all detainees for possible release at least once every six months and be required to document why detainees have not been released, including "mandatory" detainees through alternative programs.

Immigration detention should be rare and used only when strictly necessary to either ensure that noncitizens appear for their removal proceedings or to protect the public.

\subsection{Alternative-to-Detention (ATD) programs should be expanded and improved}

ICE has abundant experience in overseeing cost-effective ATD programs, which have consistently ensured high court appearance rates. ICE should expand its use of ATD programs and should 
adapt these programs in response to the COVID-19 crisis. In addition, non-profit, communitybased organizations with broad experience in running programs for persons in removal proceedings and that can draw on their extensive social service, legal and health networks and strong community ties, should no longer be excluded from federal contracts to manage ATD programs. Although DHS is required by statute to detain broad categories of non-citizens, ATD programs should be considered an alternative form of detention and made available to persons subject to mandatory detention.

\subsection{End the use of private corporations to administer immigration detention centers} Private prison corporations largely control and operate the U.S. immigrant detention system. ${ }^{[10]}$ These corporations - which answer to their shareholders and seek to maximize profit-have a deplorable record regarding the treatment and safety of detainees and facility staff, including during the COVID-19 crisis. In addition, they have a strong history of seeking to influence public policy to their financial advantage. Privatization makes it more difficult to oversee and ensure adherence by facilities to appropriate civil detention standards and to identify, correct and punish abuses of detained persons. The new Attorney General and DHS Secretary should issue a policy memorandum in the first month of the new administration ending the use of private corporations to administer immigrant detention centers.

\subsection{Strengthen mechanisms for detention oversight}

Oversight for compliance with immigrant detention standards is diffuse, convoluted and largely ineffective. The current oversight system includes: (1) site- and issue-specific investigations by the DHS Office of Inspector General (OIG); (2) inspections by a private firm of facilities that are mostly operated by private corporations; (3) infrequent inspections by ICE's Office of Detention Oversight (ODO); and (4) a Detention Monitoring Program at select facilities to promote compliance with ICE standards. The DHS Civil Rights and Civil Liberties Office works with ICE to craft policies designed to safeguard the rights of detained persons.

Since its creation in 2002, OIG has issued 39 critical reports on detention conditions. A June 26, 2018 DHS OIG report titled, "ICE's Inspection and Monitoring of Detention Facilities Do Not Lead to Sustained Compliance or Systemic Improvements," found that ICE's inspections and monitoring processes do not ensure adequate oversight or produce systemic improvements in detention conditions. The report noted that some deficiencies have remained unaddressed for years.

The new administration should create an enforceable accountability and oversight system that protects those in DHS custody. It should encourage DHS's OIG to investigate detention conditions, oversight systems and compliance with detention standards and contract terms. DHS and federal prosecutors should, in turn, carefully consider OIG's recommendations related to recovery of monies, systemic improvements in oversight, disciplinary actions, suspension of contracts and referrals for prosecution.

[10] As of November 2019, two corporations-GEO Group and CoreCivic-managed facilities that held more than one-half of all ICE detainees. According to one report, five private contractors-GEO Group, CoreCivic, LaSalle Corrections, Management \& Training Corp. and Immigration Centers of America-administered facilities with more than 75 percent of ICE detainees. 


\section{BORDER ENFORCEMENT AND ACCOUNTABILITY}

U.S. Border Patrol expenditures have increased dramatically since the early 1990s, including each year during the Trump administration, reaching nearly \$5 billion in FY2O2O. Despite these increases and an expanding operational footprint, the Border Patrol and its parent agency, U.S. Customs and Border Protection (CBP), have operated behind a veil of secrecy with little accountability and oversight, and a troubling history of abusive treatment of migrants.

\section{PROPOSALS FOR ACTION}

\subsection{Defund construction of the border wall}

The Trump administration's most publicized enforcement initiative has been to build a 2,000mile wall across the U.S.-Mexico border. When Congress funded the project at far less than requested by the administration, the President declared a national emergency at the U.S.Mexico border and transferred to the wall initiative $\$ 3.6$ billion of Department of Defense (DOD) funding for military construction projects, $\$ 2.5$ billion from the DOD counterdrug program and $\$ 601$ million from the U.S. Treasury Forfeiture Fund in FY2019.

While fencing may be effective in certain heavily crossed areas, no adequate justification has been offered for a 2,000-mile barrier. CBP has long possessed the staffing, technology, vehicle barriers, strategic fencing and resources to control the border at less cost than a physical wall and without the concomitant damage to border communities and the environment. Moreover, a wall does nothing to diminish the main source of newly undocumented persons-namely, those who overstay temporary visas. A new administration should terminate funding for the Trump administration's wall initiative and, as possible, reallocate improperly transferred funding. In addition, it should focus its diplomatic and development resources on the main drivers of migration to the United States, particularly from the Northern Triangle states of Central America.

\subsection{Review CBP stop, search and seizure policies and programs}

Under INA section 287 (a) (3), immigration officers have the power to conduct searches without a warrant "within a reasonable distance" from an external boundary (defined by regulation as 100 air miles) and to gain "access to private lands, but not dwellings, for the purpose of patrolling the border to prevent" illegal entries within 25-miles of the border. CBP's enforcement presence, which is expanding in geographic reach and intrusiveness, has generated legitimate concerns regarding warrantless searches and seizures, due process and the infringement of constitutional rights across vast stretches of the country.

A new administration should comprehensively review these statutory authorities and evaluate the resulting DHS enforcement policies and practices, with the goal of establishing effective, rights-respecting enforcement policies. 


\subsection{Change CBP's culture}

Documentation efforts by non-governmental organizations, empirical studies and complaints filed against CBP agents have revealed consistently high levels of physical and verbal abuse of migrants, including threats and racist, ethnic, sexist and homophobic epithets. The long history of abusive behavior by Border Patrol agents is interwoven with unacceptable levels of corruption and criminal violations by agents and the agency's high rate of attrition. Under the new administration, the DHS Secretary and CBP director should prioritize changing the culture that has permitted routine and widespread abuse of immigrants and border residents over many years.

Several measures can contribute to a solution. First, CBP should strengthen its hiring practices through stringent background checks, probationary periods for new officers and recruitment of more women and college-educated agents. Second, it should offer frequent training to front-line agents and supervisors and should affirm, as recommended by a 2016 report of the Homeland Security Advisory Council, the importance of the training through performance standards, reviews and rewards. Systemic challenges for the agency should be prioritized, such as: (1) the treatment of vulnerable populations; (2) adherence to constitutional norms; (3) the lawful use of force; (4) automatic referral of migrants that express a fear of returning to their home countries for "credible fear" and "reasonable fear" screening; and (5) foregoing enforcement in sensitive locations, including courthouses.

Under the Biden administration, DHS and CBP should adopt a zero-tolerance approach to verbal and physical abuse and an agency-wide commitment to identify and expeditiously address patterns of abuse. This will entail holding supervisors accountable for the conduct of their agents and evaluation of agents and supervisors based on their adherence to these standards. Supervisory and managerial evaluations, including promotions, should reflect this priority. CBP should also develop strategies to identify, promote and retain agents with a proven record of respecting the rights of migrants and residents of border communities.

\section{CBP has long possessed the staffing, technology, vehicle barriers, strategic fencing and resources to control the border at less cost than a physical wall and without the concomitant damage to border communities and the environment.}

\subsection{Strengthen systems to handle and investigate complaints and apply disciplinary processes}

Studies have demonstrated persistent inaction on complaints of alleged abuse by Border Patrol agents. In September 2014, DHS Secretary Jeh Johnson announced measures to increase the transparency and streamline the investigation of complaints filed against CBP officials. The policies allowed qualified employees of the CBP Office on Internal Affairs (OIA) to serve as "general investigators," giving them authority "to investigate or act upon claims of abuse within the organization." CBP also implemented a standardized review process for use-of-force incidents in order to expedite investigations.

The CBP Integrity Advisory Panel of the Homeland Security Advisory Council extensively 
examined CBP's disciplinary processes, response to complaints and transparency. The Council's final report on March 15, 2016 highlighted "the fragmentation of responsibility for investigating allegations of serious misconduct," the sense that misconduct complaints fell into a "black hole" and CBP's "broken" disciplinary system. It made recommendations regarding the analysis of use of force data for early identification of possible problem officers, the need for expedited and thorough investigations of all misconduct allegations and transparent action in response to all complaints. The report further called for increased investigative staffing at OIA, extending the period of probation for CBP enforcement officers and expanding its polygraph program. Additional needs, not in the Council's report, include discipline for serious misconduct that does not come to fruition, such as using weapons to threaten migrants and raising disciplinary action to a level of management commensurate with the severity of the alleged misconduct.

DHS's and CBP's new leadership should review the progress of the agency in implementing Obama-era reforms and the recommendations of the CBP Integrity Advisory Panel regarding handling and investigation of complaints of misconduct and application of disciplinary processes. Based on this evaluation, it should develop and begin to implement a plan within its first year to strengthen these systems.

\section{[The new] DHS Secretary and CBP director should prioritize changing the culture that has permitted routine and widespread abuse of immigrants and border residents over many years.}

\subsection{Limit the reach of expedited removal}

The Illegal Immigration Reform and Immigrant Responsibility Act of 1996 (IIRIRA) provided for "expedited removal" of inadmissible persons who lacked proper immigration documents or committed misrepresentation or fraud in seeking entry. By regulation, expedited removal was originally restricted to persons arriving at ports-of-entry. In 2004, expedited removal was expanded to cover persons who entered the United States without authorization and were apprehended within two weeks of entry and no more than 100 miles from the border. On July 23, 2019, DHS sought a further dramatic expansion, announcing via notice in the Federal Register that expedited removal would henceforth apply to persons anywhere in the country who lacked proper documentation and could not prove they had been in the United States for at least two years. In June 2020, a federal appeals court rejected a claim that the expansion violated the Administrative Procedure Act; it permitted a constitutional challenge to the program to continue. ${ }^{[11]}$

The DHS Secretary in the new administration should issue a notice limiting expedited removal to persons without proper documents at land or sea ports-of-entry and to unauthorized migrants arrested in the near vicinity of a land border who have resided continuously in the United States for 14 days or less. The notice should also withdraw past directives and notices that extended expedited removal beyond these areas, including the Trump administration notice of July 23, 2020. ${ }^{[12]}$

[11] Make the Road v. Wolf, D.C. Cir., June 23, 2020.

[12] The proposal to limit the reach of expedited removal through administrative action should not be read to indicate support of the expedited removal process overall. 


\subsection{Ensure appropriate reception, care and treatment of unaccompanied children at the border and throughout the U.S. immigration system}

New barriers to asylum have subverted long-standing protections for unaccompanied migrant children. Even if a new administration removes these barriers, most children seeking protection at the U.S.-Mexico border will first encounter CBP agents, who are unprepared and disinclined to meet their unique needs. The Biden administration should pivot from a security-and enforcementbased approach to unaccompanied children to a humanitarian approach that prioritizes the children's best interests. The new DHS Secretary should issue a policy memorandum detailing the agency's commitment to (1) the "best interests of the child" throughout the immigration system; (2) screening and training partnerships with nongovernmental organizations that enjoy expertise in child welfare and development and in trauma-informed treatment of children; and (3) the rapid identification of children as unaccompanied and the transport of these children to ORR shelters within 24 hours.

\section{INTERIOR ENFORCEMENT}

In its first week in office, the Trump administration issued an executive order setting forth immigration enforcement priorities so broad that, in effect, they failed to establish any priorities. While the highest percentage of non-citizens arrested by ICE's Enforcement Removal Operations in FY2019 had criminal convictions, many of those were for relatively minor crimes, such as immigration and minor traffic offenses. ICE also arrested large numbers of immigrants without criminal records. Priorities are necessary for any rational set of enforcement policies because, although well-funded, ICE and DHS lack the resources to respond to every violation of the law within their jurisdictions. There are also cases that should not be pursued for humanitarian or policy reasons. A strategy to arrest anyone and everybody produces arbitrary results and the unwise use of resources in individual cases where removal serves no law enforcement or public safety goal.

State and local law enforcement agencies (LEAs) are involved in interior enforcement efforts in two important ways. The Secure Communities program, initiated in 2008 under the Bush Administration, identified and sought to remove non-citizens arrested and held in local jails. Under the program, when state and local agencies submitted fingerprints of arrested persons to the FBI, the FBI sent the fingerprints to DHS to check against immigration databases. If DHS determined that the person was unlawfully in the United States, it could undertake enforcement action to remove the person from the United States. Secure Communities was suspended by the Obama administration in 2014; in its place, the Obama administration instituted the Priority Enforcement Program (PEP). PEP restricted ICE enforcement to serious criminal cases and asked that local authorities notify ICE before an identified person was released (rather than detain the person). The Trump administration ended PEP and reinstated Secure Communities shortly after taking office.

The second form of federal-state cooperation is provided by Memoranda of Agreement (MOAs) adopted pursuant INA section $287(\mathrm{~g})$, in which DHS delegates immigration enforcement to state and local authorities. Currently there are two types of MOAs: (1) jail enforcement agreements, which authorize LEAs to interrogate and charge with immigration violations persons arrested on non-immigration grounds, subject to ICE supervision; and (2) Warrant Service Officer agreements 
(added by the Trump administration), which authorize LEAs to arrest persons in local jails identified by ICE as chargeable on immigration grounds. As of September 2020, ICE has 77 jail enforcement agreements in 21 states and 73 Warrant Service Officer agreements in 11 states.

\section{PROPOSALS FOR ACTION}

\subsection{Restore meaningful enforcement priorities and prosecutorial discretion to the} U.S. immigration system

In 2014, DHS Secretary Jeh Johnson set DHS enforcement priorities that focused on the most severe and consequential immigration violations. The Johnson memorandum set forth three tiers of enforcement priorities:

- non-citizens deemed a threat to national security, unlawful entrants arrested at the border (to dissuade others from coming), criminal gang members and participants, convicted felons and "aggravated felons";

- non-citizens convicted of three or more misdemeanors or one significant misdemeanor, certain unlawful entrants or re-entrants and persons deemed to have abused visa or visa waiver programs; and

- non-citizens issued a final order of removal.

The Johnson memorandum also allowed DHS officers to consider a range of factors that-in individual cases that would otherwise fall within its enforcement priorities-militated against arrest and removal. These factors included length of time in the United States, family or community ties, military service and humanitarian considerations.

The DHS Secretary in the new administration should issue a policy memorandum that sets forth meaningful immigration enforcement priorities and prosecutorial discretion guidelines, using the Johnson memorandum as a reference point. Some changes in the Johnson criteria would be advisable, including reconsideration of the "significant misdemeanor" enforcement priority and recognition that some "aggravated felons" may, in fact, have committed relatively minor crimes years in the past.

A strategy to arrest anyone and everybody produces arbitrary results and the unwise use of resources in individual cases where removal serves no law enforcement or public safety goal.

\subsection{Limit the role of local and state authorities in immigration enforcement; restore PEP and end section 287(g) MOAs}

Restore PEP

The Obama administration terminated Secure Communities because LEAs refused to cooperate and lawsuits were filed challenging the constitutionality of honoring ICE detainers beyond the period in which LEAs would otherwise hold an immigrant in custody. It established PEP to ensure that ICE requested detainers only for non-citizens charged with serious crimes or deemed a public safety threat. The reinstitution of Secure Communities by the Trump administration has gone hand-in-hand with its dramatic expansion of ICE priorities; 
essentially ICE may now request a detainer for any person arrested by local authorities that ICE determines is unlawfully in the country. This expansion incentivizes pretextual arrests at the local level, which may often be based on racial profiling. PEP establishes an appropriate role for LEAs in furthering federal enforcement priorities.

End section $287(g)$ agreements

Enforcement of U.S. immigration law is and should remain a federal function. Delegations to local authorities have made immigrants fearful to cooperate with the police and have led to unacceptable patterns of racial profiling and civil rights abuses. ICE training and oversight has been inadequate (under a Warrant Service Officer agreement, local authorities are given only 8 hours of training). With PEP in place, ICE can inform LEAs of non-citizens who are a danger to the community and should be removed.

\section{IMMIGRATION-RELATED CRIMINAL PROSECUTIONS}

Prosecutions for illegal entry and re-entry after removal now account for more than half of all federal criminal prosecutions in the United States. During his first week in office, President Trump issued an executive order calling on the Attorney General to "establish prosecution guidelines and allocate appropriate resources to ensure that federal prosecutors accord a high priority to prosecutions of offenses having a nexus to the southern border." In an April 11, 2017 memorandum, Attorney General Jeff Sessions directed federal prosecutors to develop guidelines for "the prosecution of firsttime improper entrants" and to consider pursuing "felony prosecutions" for a range of other more serious offenses involving illegal entry and re-entry. On April 6, 2018, Sessions announced a "zero tolerance" approach to unlawful entries and directed federal prosecutors to prosecute all improper entry violations "to the extent practicable."[13] Immigration-related prosecutions, including of asylum-seekers and first-time entrants, rose from 59,797 to 99,479 between FY2017 and FY2018, and reached 106,312 in FY2019, driven overwhelmingly by improper entry prosecutions.

\section{PROPOSAL FOR ACTION}

\subsection{Deprioritize prosecutions for improper entry and re-entry, and forego prosecutions of asylum-seekers}

Immigration prosecutions for improper entry monopolize federal law enforcement and judicial resources and separate families. They also raise due process concerns, occurring through a streamlined system in which judges accept guilty pleas from dozens of people at a time and federal public defenders represent multiple defendants with whom they can meet for only a few minutes.

The Attorney General in the Biden administration should issue a memorandum that directs federal prosecutors to develop prosecution guidelines that do not prioritize prosecutions for improper entry or re-entry, absent special factors such as multiple illegal entries or the re-entry

[13] 8 USC section 1325(a) applies to migrants who enter the United States without proper inspection at a port of entry, avoid examination or inspection or make false statements while entering or attempting to enter. The violation of section 1325 (a) as a first offense is a misdemeanor punishable by a fine, up to six months' imprisonment, or both. 
of persons removed for violent and other severe crimes. In addition, entrants without inspection who are pursuing asylum, withholding of removal or Convention against Torture claims should not be prosecuted. The new DHS Secretary should issue a memorandum directing CBP to establish a streamlined and responsive process for previously prosecuted and deported asylumseekers and others to file motions to reopen and rescind DHS removal orders.

\section{LEGAL ACCESS AND REPRESENTATION; ADJUDICATION BACKLOGS}

Legal representation is a key component of due process in the removal adjudication system, given the high stakes, the complexity of the law and the adversarial nature of the proceedings. Many studies have highlighted the importance of legal representation to case preparation, outcomes and the efficiency of removal proceedings.

Since 2000,EOIR has administered several successfullegalorientation, facilitation and representation programs. EOIR's signature legal access initiative, the Legal Orientation Program (LOP), is funded to operate in 46 detention centers in 15 states (although some of these detention centers are not now holding detainees). The LOP offers group orientation sessions on removal proceedings and relief from removal. It also provides intensive individual orientation to participants and self-help workshops for those who wish to depart voluntarily, pursue relief from removal or request release on bond. It further refers select participants to pro bono legal assistance.

The National Qualified Representation Program (NQRP) provides legal counsel to non-citizens in removal proceedings who are not competent to represent themselves. This program, which operates in all but roughly 18 immigration courts, is a result of the Franco-Gonzalez v. Holder class action lawsuit on behalf of unrepresented detainees in Arizona, California and Washington with "mental disorders."

The Board of Immigration Appeals (BIA) Pro Bono Project secures legal representation in immigration cases under appeal. Since its inception in 2001 , the project has provided representation to close to 1,200 persons. The Trump administration has taken the position that the use of nongovernmental screeners-a centerpiece of the program-violates the prohibition against the disclosure to third parties of information "contained in or pertaining to any asylum application" or "records pertaining to" credible fear or reasonable fear determinations, and that Privacy Act protections continue to apply to lawful permanent residents seeking cancellation of removal. As a result, screening of cases must now be conducted solely by government attorneys, before transcripts of hearings or the immigration judge decision is available. Very few cases have been matched with counsel due to these new limitations.

In addition to these EOIR programs, the Secretary of Health and Human Services has an affirmative responsibility to ensure "to the greatest extent practicable" that unaccompanied children in federal custody or who were once in federal custody have legal counsel. 
The last eight years has also seen the establishment and proliferation of "universal representation" programs. These programs-which are funded by municipalities, counties, states and private funders-represent all or a substantial number of persons in removal proceedings in particular jurisdictions or geographic areas. The universal representation model offers representation without reference to the likelihood of success on the merits. Its overarching goal is not just to provide representation in meritorious cases, but also to enhance access to justice and the integrity of the removal system overall. Piloted in New York City in 2013, the model has since expanded to 18 cities and counties in nine states.

Legal orientation, access and representation programs have been hampered by untenable immigration court and affirmative asylum backlogs.

\section{PROPOSALS FOR ACTION}

\subsection{Strengthen and expand the LOP, NQRP and BIA Pro Bono programs}

The DOJ should announce its intention and develop a plan to expand LOP to: (1) all U.S. detention centers; (2) all detainees, including those subject to expedited removal and reinstatement of removal; and (3) all non-detained populations prior to their initial master calendar hearings. It should also announce its intention and outline a plan to expand the NQRP to all immigration courts and to cover additional categories of cases (such as unaccompanied children) in which due process considerations require legal representation. EOIR should fully restore the BIA Pro Bono Project and resolve any privacy concerns related to the screening of anonymized case files on appeal under this project.

\subsection{Promote and expand the universal representation model}

The federal government supports legal orientation, but, other than in extreme cases, it does not fund direct representation. However, it can play a powerful role in linking public and private entities that are committed to expanding legal services for immigrants and affording due process in the removal adjudication system. To this end, the new administration should convene a summit in its first year - with participation by DHS and DOJ, states, localities, private funders, legal service networks, bar associations, immigration coalitions, CBOs, academia and research institutions-to develop an action plan to promote, expand and attract funding for universal representation programs.

\subsection{Ensure that all unaccompanied children have legal counsel}

Unaccompanied children cannot effectively represent themselves, and they face immense barriers in securing legal counsel and protection. ORR has helped to secure representation for children in custody whose cases have moved forward to the pleading stage. However, all unaccompanied children need legal counsel even before this point, in part to evaluate their eligibility for legal relief. ORR should continue to commit funds and it should seek additional funds to support legal services for unaccompanied children by leveraging partnerships with pro bono service providers. EOIR's LOP and NQRP programs should be extended to unaccompanied children. 


\subsection{Establish an inter-agency working group to develop actionable proposals to reduce immigration court and affirmative asylum backlogs}

Adjudication backlogs constitute a significant obstacle to a viable asylum and immigration system and to effective legal representation. The USCIS Asylum Corps adjudicates affirmative asylum applications and makes "credible fear" and "reasonable fear" determinations for asylumseekers who are subject to expedited removal and reinstatement of removal. The asylum backlog for cases not in removal proceedings reached nearly 340,000 cases by late 2019; the Report to Congress on Proposed Refugee Admissions for FY2020 projected that it would exceed 500,000 by year-end. The Trump administration has used the high affirmative asylum backlog to justify capping refugee admissions at historically low levels. Immigration Court backlogs, in turn, have more than tripled over the last decade, to 1.25 million by August 2020.[14] Backlogs are due to high volumes of cases, insufficient funding to adjudicators, the failure to exercise meaningful prosecutorial discretion, systemic inefficiencies and poor management.

The Biden administration should constitute a high-level inter-agency working group, with select public and private advisors, tasked with developing actionable proposals to reduce immigration court and affirmative asylum backlogs to manageable levels.

\section{COVID-RELATED POLICIES}

In response to the COVID-19 pandemic, President Trump has banned entry to the United States of an extremely large number of foreign nationals. While current green-card holders and medical personnel are generally excluded from the bans, the restrictions apply to: (a) persons who have been in China, most EU states, Iran and Brazil in the previous 14 days; (b) persons seeking initial entry to the United States on an immigrant visa (except immediate relatives of U.S. citizens); (c) "non-essential" travelers from Mexico and Canada; and (d) persons seeking to enter the United States on a number of non-immigrant visas (including H-1B, H-2B, L and some categories of J).

ICE enforcement efforts were initially reduced during the pandemic. As the pandemic has progressed, however, ICE has resumed large-scale arrests of immigrants, including ordinary status violators. It has also vowed to pursue targeted enforcement in "sanctuary cities." At this writing, roughly 17,500 non-citizens are being detained pending immigration proceedings, more than 7,000 immigrant detainees have tested positive for COVID-19, and many more have contracted the virus but not been tested.. A number of lawsuits have successfully challenged the continued detention of at-risk non-citizens (including children, the elderly and persons with underlying health conditions). ${ }^{[15]}$

\section{PROPOSALS FOR ACTION}

\subsection{Immediate review of the bans}

The new administration should announce a review of all COVID-related bans to examine whether the health and economic benefits of the bans outweigh the costs to U.S. and immigrant families

[14] This figure does not include hundreds of thousands of administratively closed cases that could be re-calendared and returned to an active court docket due to a decision by Attorney General Sessions.

[15] The CDC order authorizing the expulsion of undocumented migrants at the border is discussed in the Asylum section of this report. 
and U.S. employers and whether sensible alternatives exist (such as 14-day quarantines, testing before arrival). There should be a presumption of expiration of such bans after a set period of time.

If public health experts determine that particular entry restrictions are necessary to substantially reduce the incidence or transmission of COVID-19 in the United States, the administration could issue a new, temporary section 212 (f) proclamation. Any such proclamation should conform with the limitations set forth in the NO BAN Act, HR 2214, including narrow tailoring and notification to Congress as contemplated in that proposed legislation.

\subsection{Release at-risk detainees}

DHS should develop and implement a screening protocol to guide detention decisions and provide for the release of vulnerable, at-risk detainees during the pandemic.

\section{SEGREGATION OF RESPONSIBILITIES WITHIN DHS}

In creating DHS, the Bush administration and Congress recognized both the need for coordination among DHS's constituent agencies as well as the distinct missions, responsibilities and functions of each of these agencies. Critics had long contended that locating enforcement and benefit responsibilities in the same agency compromised INS's ability to fulfill either of its missions. In this context, the creation of DHS was viewed as a positive step toward greater separation of these functions. Section 441 of the Homeland Security Act of 2002 listed the enforcement functions that would be transferred to DHS's new Under Secretary for Border and Transportation Security, while section 451 (b) set forth the immigration application and benefit responsibilities of DHS's Bureau of Citizenship and Immigration Services.

The new administration should review whether DHS has sufficiently prioritized both its benefits and enforcement functions and adequately segregated the responsibilities of these distinct agencies so that they operate as competently and efficiently as possible. In at least two kinds of situations, the lines between USCIS and CBP have been inappropriately blurred.

\section{PROPOSALS FOR ACTION}

\subsection{End the practice of Border Patrol agents serving as Asylum Officers; require CBP officers to abide by their legal responsibility to refer migrants subject to expedited removal and who communicate fear of return to "credible fear" or "reasonable fear" interviews}

CBP officers are required by law to refer persons for "credible fear" and "reasonable fear" interviews when circumstances so merit. They have consistently failed to do so. Nonetheless, in April 2019, CBP initiated a pilot program to train Border Patrol agents to serve as Asylum Officers (AOs) and to conduct "credible fear" interviews of asylum-seekers at the U.S.-Mexico border. 
Under this program, they would replace specially trained USCIS AOs who have been vested with this responsibility. According to reports, Border Patrol agents have conducted credible fear interviews like "criminal interrogations" and have referred a far lower percentage of asylumseekers than USCIS AOs to removal proceedings, where they can pursue their asylum claims. This is not surprising since many Border Patrol agents view asylum through an enforcement lens, harbor negative views of asylum-seekers and believe they fabricate their claims. In addition, asylum-seekers are likely to distrust agents and be reluctant to share with them the details of their claims.

The Biden administration should terminate the pilot program, end the use of Border Patrol agents as AOs and ensure that USCIS Asylum Offices have sufficient resources and staffing to handle their many responsibilities, including credible fear and reasonable fear determinations.

The new DHS Secretary should also issue a policy memorandum that directs CBP officers, including the Border Patrol, to abide by their legal responsibility to refer migrants who indicate a fear of violence to credible fear or reasonable fear interviews. The memorandum should also direct border officials to refrain from hostile and dismissive statements regarding the merits of asylum claims and their likelihood of success, to enter accurate information on completed forms, to inform migrants of the possibility of protection and to allow asylum-seekers to review sworn statements before signing them.

\subsection{Limit referrals to removal proceedings to cases involving fraud or when USCIS is statutorily required to refer}

Prior to 2018, USCIS issued notices to appear (NTAs), the charging document that initiates removal proceedings, primarily in cases in which it was legally compelled to do so. A November 2011 policy memorandum limited USCIS issuance of NTAs to situations "that promote the sound use of the resources of the Department of Homeland Security and the Department of Justice to enhance national security, public safety, and the integrity of the immigration system." On June 28,2018 , USCIS issued a policy memorandum titled "Updated Guidance for the Referral of Cases and Issuance of Notices to Appear in Cases Involving Inadmissible and Deportable Aliens" that significantly expands the situations in which USCIS is directed to issue NTAs, including those in which an application, petition or benefit request is denied and the non-citizen is not "lawfully present." The intent and effect of the policy is to deter applicants for family-based adjustment of status, TPS renewal and naturalization from seeking these immigration benefits. In addition, the policy negatively affects professional workers and students, and clogs an already overburdened immigration court system.

USCIS should limit referrals to removal proceeding to cases involving fraud or when USCIS is statutorily required to refer.
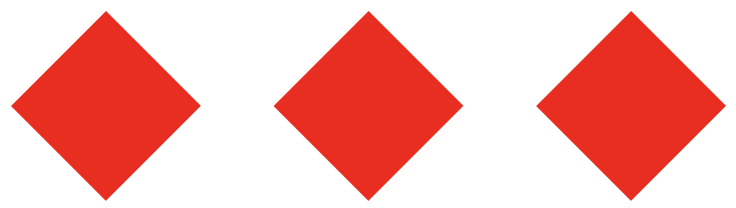


\section{NOVEMBER 2020}

\section{IMPROVING THE U.S. IMMIGRATION SYSTEM IN THE FIRST YEAR OF THE BIDEN ADMINISTRATION}

Contact Information:

T. Alexander Aleinikoff aleinikoff@newschool.edu

Donald Kerwin

dkerwin@cmsny.org

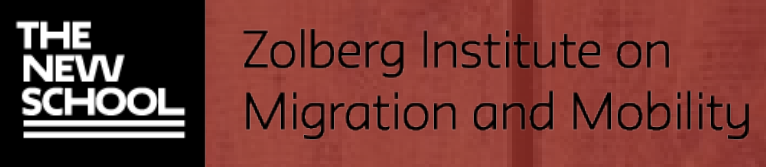

Report designed by: Catherine McGahan, Associate Director, Zolberg Institute on Migration and Mobility, The New School

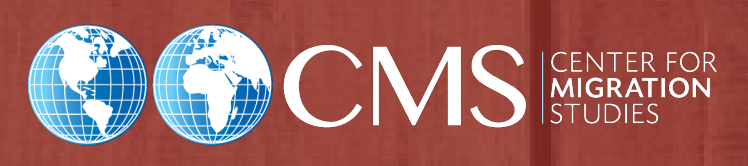

